\title{
Grice and Kant on Maxims and Categories
}

\author{
Christoph Schamberger ${ }^{1}$ (D) $\cdot$ Lars Bülow $^{2}$
}

Received: 26 April 2020 / Revised: 31 March 2021 / Accepted: 21 June 2021 /

Published online: 16 September 2021

(c) The Author(s) 2021

\begin{abstract}
Apart from a passing reference to Kant, Grice never explains in his writings how he came to discover his conversational maxims. He simply proclaims them without justification. Yet regardless of how his ingenious invention really came about, one might wonder how the conversational maxims can be detected and distinguished from other sorts of maxims. We argue that the conversational maxims can be identified by the use of a transcendental argument in the spirit of Kant. To this end, we introduce Grice's account of conversational maxims and categories and compare it briefly with Kant's thoughts on categories. Subsequently, we pursue a thought experiment concerning what would happen if speakers constantly broke one or another of the maxims. It seems that it would not be possible for children to recognize a significant number of lexical meanings under such circumstances. Hence, the conversational maxims are rules whose occasional application is a necessary condition of language and conversation.
\end{abstract}

Keywords Conversational maxims · Categories · Transcendental argument · Grice · Kant

\section{Introduction}

Famously, Paul Grice draws a distinction between speaker meaning (utterer's meaning, for Grice) and sentence meaning. By distinguishing a number of conversational maxims, such as "Avoid ambiguity," he is able to explain the generation of conversational implicatures, which are part of the speaker meaning but not of the sentence meaning. However, apart from a passing reference to Kant (Grice, 1989a, p. 26), Grice is silent on the question of how he came to discover the conversational maxims and has little to say about their epistemological status. He simply stipulates

Christoph Schamberger

christoph.schamberger@web.de

1 Department of Philosophy, Humboldt University of Berlin, Berlin, Germany

2 Department of German Studies, University of Vienna, Vienna, Austria 
them and argues that it is profitable and therefore reasonable to observe them. Yet, one may respond, the same goes for all sorts of other maxims.

The conversational maxims have since become an object of both philosophical and linguistic study. Various scholars propose alternative principles or offer different explanations for the generation of implicatures (Bach, 2012; Davis, 2019). Both Neoand Post-Gricean pragmatics cut the number of conversational maxims. The most prominent approaches have been introduced by Horn (1984, 2007, 2012), Levinson (2000), and relevance theorists (Sperber \& Wilson, 1995; Carston, 2002). Whereas Horn and Levinson develop principles for drawing pragmatic inferences to implicatures, relevance theorists assume that inferences are based on a more fundamental cognitive principle, i.e., that ostensive stimuli need to be understood as acts of intentional communication. "These include not just utterances of linguistic expressions, but also the various paralinguistic and non-linguistic devices that accompany them, as well as non-verbal communication." (Hall, 2018, p. 87) Another debate has arisen about the extent to which conversational maxims or principles of inference can be derived psychologically and whether psychological plausibility is an appropriate measure of success for a pragmatic theory (Carston, 2005; Horn, 2005, 2006).

We will not take a stand on these debates. Instead, we seek to establish the conversational maxims in a way which is more akin to Grice's own approach. We would like to show that they can be recognized as rules whose occasional application is a necessary condition of language and conversation. We shall defend this claim with a transcendental argument that builds upon some thoughts from Kant's transcendental deduction of the categories.

In the next section, we briefly examine the nature of conversational maxims. We distinguish them from other maxims and consider their relation to conversational categories. Note that we do not take account of alternative principles such as those proposed by Sperber \& Wilson, Levinson, or Horn; thus, we will consider only Grice's own conversational maxims in this paper. Since Grice refers to Kant's categories, a brief look at Kant's own considerations will be helpful. The third section offers a transcendental argument to answer the epistemological question of how the maxims can be identified. In the final section, we discuss this argument and compare it to other transcendental arguments.

\section{Conversational Maxims and Categories}

Conversations are governed by several kinds of maxims, and it is sometimes difficult to distinguish the conversational maxims (see a full list of them in Table 1 at the end of the section) from other maxims. A first hint as to how we might do this is provided in the following quotation. After introducing the conversational maxims, Grice writes:

There are, of course, all sorts of other maxims (aesthetic, social, or moral in character), such as "Be polite," that are also normally observed by participants in talk exchanges, and these may also generate nonconventional implicatures. The conversational maxims, however, and the conversational implicatures connected with them, are specially connected (I hope) with 
Table 1 Table of Maxims

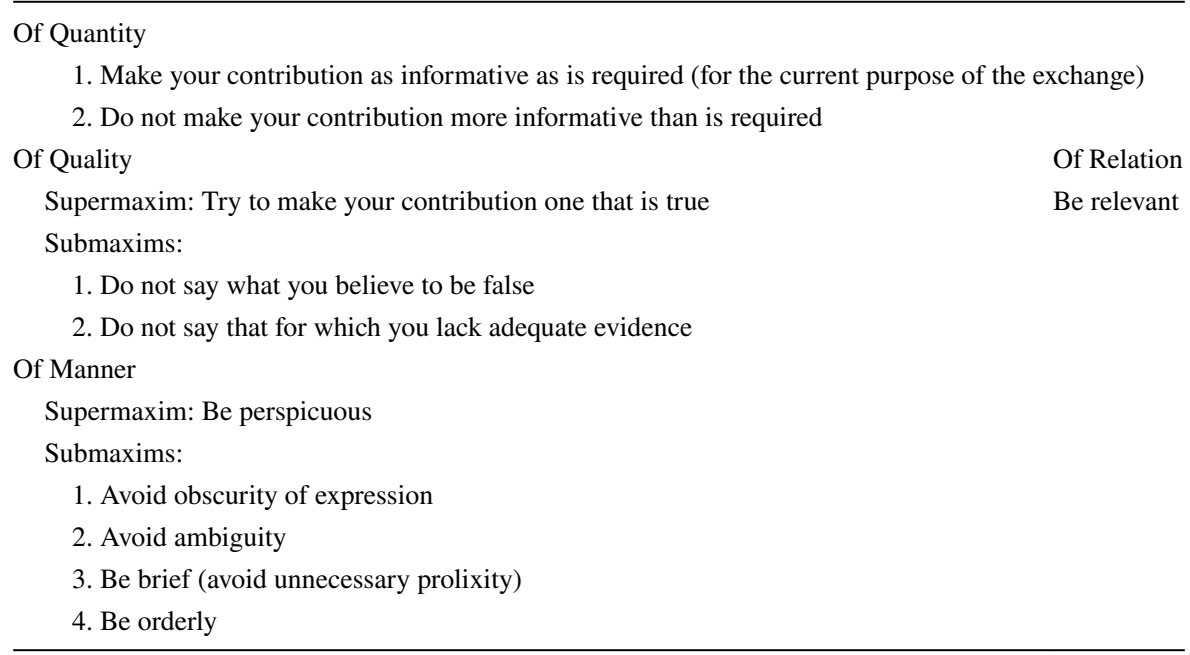

the particular purposes that talk (and so, talk exchange) is adapted to serve and is primarily employed to serve. I have stated my maxims as if this purpose were a maximally effective exchange of information; this specification is, of course, too narrow, and the scheme needs to be generalized to allow for such general purposes as influencing or directing the actions of others. (Grice, 1989a, p. 28)

Even though Grice distinguishes between conversational, aesthetic, social, and moral maxims, it does not follow that these classes of maxims are mutually exclusive. For example, the maxims of Quality, such as "Do not say what you believe to be false," might also be regarded as moral maxims. Discourse ethics proposes quite similar rules that are said to "have an ethical import" (Habermas, 1990, p. 88). However, according to Grice, conversational maxims differ from all sorts of other maxims in that they reveal what speakers have to do if they strive for a maximally effective exchange of information.

Unfortunately, Grice does not explain what he takes a maximally effective exchange of information to be. He simply declares that it is "the standard type of conversational practice" (Grice, 1989a, p. 29) and assumes that a maximally effective exchange of information is one that implements all conversational maxims. A maximally effective exchange of information should not be equated with a telegraphic style of communication, because a talk exchange can only be effective if it also considers the hearer's needs and background knowledge. Here, room is left for empirical research, and any full account of maximal effectiveness would have to explain which maxims are most significant in particular situations. But Grice does not seem interested in this question. So, let us take "maximally effective exchange of information" as a technical term and define it as a talk exchange whose participants fulfill all conversational maxims simultaneously. (Below, we often omit the 
adjective "conversational" when we speak about Grice's conversational maxims and conversational categories, as long as there is no risk of confusion with the Kantian maxims and categories.)

Grice claims that following the maxims "will, in general, yield results in accordance with the Cooperative Principle" (ibid., p. 26). The Cooperative Principle (CP, for short) says: "Make your conversational contribution such as is required, at the stage at which it occurs, by the accepted purpose or direction of the talk exchange in which you are engaged." (Ibid.) However, the relation between the CP and the maxims is intricate. According to Grice, the CP must not only be observed in exchanges of information, but in any conversation. If someone is caught breaking this principle, the conversation may be impeded or even wrecked. One may therefore say that the $\mathrm{CP}$ is a strict rule that normally allows for no exceptions. By contrast, maxims are no strict rules, since conversation does not require sticking to them. For example, speakers frequently flout the maxims; that is, they blatantly fail to fulfill them, say, by using irony or metaphor, without violating the CP. These cases characteristically give rise to conversational implicatures (ibid., p. 30), which we do not have to elucidate here as they have been discussed a great deal in the literature (e.g., Bach, 2012; Horn, 2012). In these cases, the language game is usually not impeded and can be continued smoothly. The upshot is that the maxims are not derivable from the $\mathrm{CP}$, or from conditions under which the $\mathrm{CP}$ is observed, because it is perfectly possible for speakers to observe the $\mathrm{CP}$ without observing all maxims.

Instead, Asa Kasher proposes to derive all conversational maxims from a general rationality principle $(\mathrm{R})$ : "Given a desired end, one is to choose that action which most effectively, and at least cost, attains that end, ceteris paribus." (Kasher, 1976, p. 205; Kasher, 1982, p. 32) The maxims do not follow from (R) immediately, of course, but under some assumptions. For example, the speaker must not desire to deceive the audience, as this end can often be attained most effectively by saying something he believes to be false, which in turn violates the maxim "Do not say what you believe to be false." But when we take the maximally effective exchange of information to be the desired end of a talk exchange, the maxims follow from (R) more or less straightforwardly (ibid., p. 33). So, in contrast to Grice, Kasher provides a justification of the maxims. At the same time, he can dispense with the $\mathrm{CP}$. This is definitely an advantage, because the CP rests on the controversial assumption that there is a (mutually) accepted purpose or direction for each stage of a talk exchange (ibid., pp. 38-39).

Because (R) is not explicitly restricted to speech acts, it allows not only for the derivation of conversational maxims but of more general principles. For example, the supermaxim "Try to make your contribution one that is true" may be considered an instance of the more general principle "For attaining your ends, try to put the means at your disposal to their standard use, ceteris paribus" (ibid., p. 37). These general principles (for a list of them, see Kasher, 1976, p. 203) apply to all kinds of intentional behavior (Kasher, 1991a, p. 577; Kasher, 1991b, p. 139) and its products, such as paintings (Kasher, 1982, pp. 40-42).

In the next section, we would like to ask why speakers do observe the maxims, and thus the rationality principle $(\mathrm{R})$, at all. Sure, whenever they desire to exchange information maximally effective, they certainly have to abide by $(\mathrm{R})$ and the maxims. 
But why do they aim for a maximally effective exchange of information? As Kasher (1976, p. 203) points out, people sometimes do not choose the most effective and least-cost actions, and so they violate $(\mathrm{R})$. Moreover, they sometimes pursue ends which can best be achieved by violating one of the maxims - deceiving is a case in point. However, we would like to demonstrate that it is not possible to abandon one or another of the maxims permanently. First, though, let us briefly compare Grice's and Kant's considerations on maxims and categories.

In proposing four conversational categories and a greater number of conversational maxims, Grice deliberately gives credit to Kant. Both pursue formidable goals: while Kant investigates the conditions of the possibility of both experience and the objects of experience (B 197), ${ }^{1}$ Grice inquires "into the general conditions that, in one way or another, apply to conversation as such, irrespective of its subject matter" (Grice, 1989a, p. 24).

For Kant, the application of the categories makes any type of experience possible. Categories are "pure concepts of the understanding, which apply to objects of intuition in general a priori" (B 105). Kant regards any concept as "a rule of the synthesis of perceptions" (B 750; cf. B 180, A 106). This rule is provided by the understanding. For that reason, the understanding is "the faculty of rules" (B 171; cf. B 197, A 126). The categories are special in at least two respects: First, they give "unity to the mere synthesis of representations" (B 105) and thus make it possible to recognize objects (B 146). Second, they are pure concepts, which means that they are possible a priori (B 75). A priori concepts are contained in the understanding of the subject (B 106), that is, their source is the understanding and not sensory experience (cf. Pereboom, 2019).

Kant also works out rules for "the application of the pure concepts of understanding to possible experience" (B 199). These rules are labeled "principles of pure understanding" (B 197). They differ from the rules of other concepts (i.e., empirical concepts, such as "dog," and pure sensible concepts, such as "triangle") in that a subject cannot but follow them (B 180). Consequently, Kant formulates them as descriptive sentences. For example, the principle of pure understanding for the category "cause and effect," the famous "principle of temporal sequence according to the law of causality," reads as follows: "All alterations occur in accordance with the law of the connection of cause and effect" (B 232).

Grice's maxims are akin to Kant's categories in that both are rules. However, unlike principles of pure understanding, speakers can break the conversational maxims and, in practice, often do break them. Grice deviates from Kant also in the number of categories that he identifies. Kant lists twelve categories, which he sorts into four groups (or “titles," B 95) called Quantity, Quality, Relation, and Modality; each group contains three categories (B 106). Grice distinguishes only four categories and uses the labels of Kant's groups of categories for his own categories: "Echoing Kant, I call these categories Quantity, Quality, Relation, and Manner" (Grice, 1989a, 26). ("Manner" is a loose translation of Kant's term "Modalität," which is translated as "Modality" in most English editions.)

\footnotetext{
${ }^{1}$ The Critique of Pure Reason (Kant, 1998) is cited by page numbers in the original first (A) and second (B) editions (1781/1787).
} 
The latter remark, together with the fact that Grice does not declare what exactly he understands by "category," has led to some confusion. A number of scholars ignore the difference between categories and maxims and instead lump them together (Levinson, 1983, pp. 101-102; Keller, 1995, p. 6; Hall, 2018, p. 76). Grice may have contributed to this confusion of categories and maxims with his "Retrospective Epilogue," written shortly before his death, where he loosely talks about "the maxim of Quality" and "the maxim of Quantity" (Grice, 1989d, pp. 371-372).

Other scholars consider the categories as groups, or classes, of maxims. They regard the difference between categories and maxims as a formal difference between groups and their members (Levinson shifts to this interpretation in Levinson, 2000, pp. 14-15; Bach, 2012, pp. 56-57; Horn, 2012, pp. 74-75; Traugott, 2012, p. 551). This interpretation is suggested by the fact that Grice explicitly subordinates the maxims to the categories: "One may perhaps distinguish four categories under one or another of which will fall certain more specific maxims and submaxims" (Grice, 1989a, p. 26). Note also that Grice does not claim that a category can be reduced to certain maxims. Although it might seem natural to identify the category of Relation with its only maxim "Be relevant," Grice consistently distinguishes between them (ibid., p. 27). So, Grice uses the term "category" quite differently from Kant; he may have used "group" or "class" instead.

Just as Kant divides his twelve categories into four groups, Grice divides his maxims into four groups, and we can arrange them in Table 1 according to Kant's table of categories (B 106; cf. Rolf, 1994, p. 104; Rolf, 2013, p. 46) ${ }^{2}$ :

\section{A Transcendental Argument for Conversational Maxims as Necessary Conditions of Language and Conversation}

In what follows, we want to show how Kant's thoughts on categories can be made fruitful for investigating Grice's conversational maxims: Specifically, Grice's maxims can be identified by the use of a transcendental argument in the spirit of Kant.

Speakers regularly proceed in the manner prescribed by the conversational maxims: "It is just a well-recognized empirical fact that people do behave in these ways; they learned to do so in childhood and have not lost the habit of doing so" (Grice, 1989a, p. 29). But, for two reasons, it is virtually impossible to recognize the maxims solely through observation of linguistic usage. First, other maxims are also regularly fulfilled by the participants of talk exchanges. Second, there are still many situations where speakers do not act in accordance with the conversational maxims (the same is also true for most non-conversational maxims). As noted above, speakers frequently flout maxims, and later we will mention some other ways in which they may fail to fulfill a maxim. Conversational maxims are so often broken that it is impossible to detect them by observation alone.

\footnotetext{
2 The maxims are quoted from Grice (1989a, pp. 26-27). In a later paper, Grice proposes a fifth maxim of Manner: "Frame whatever you say in the form most suitable for any reply that would be regarded as appropriate" (Grice, 1989b, p. 273).
} 
However, Grice is not limited to empirical methods and pursues another strategy instead: He wants to show that it is reasonable to fulfill the maxims.

I am, however, enough of a rationalist to want to find a basis that underlies these facts, undeniable though they may be; I would like to be able to think of the standard type of conversational practice not merely as something that all or most do in fact follow but as something that is reasonable for us to follow, that we should not abandon. (Ibid., p. 29)

Grice does not here state that it is always unreasonable to break the maxims. But, according to him, it would be unreasonable to abandon them completely, since fulfilling them allows us to attain the central goals of conversation:

I would like to be able to show that observance of the Cooperative Principle and maxims is reasonable (rational) along the following lines: that anyone who cares about the goals that are central to conversation/communication (such as giving and receiving information, influencing and being influenced by others) must be expected to have an interest, given suitable circumstances, in participation in talk exchanges that will be profitable only on the assumption that they are conducted in general accordance with the Cooperative Principle and the maxims. (Ibid., pp. 29-30)

This passage is difficult to interpret; we read it as suggesting an argument along the following lines:

Talk exchanges are profitable if and only if they are conducted in general accordance with the $\mathrm{CP}$ and the conversational maxims.

Profitable talk exchanges are reasonable.

Therefore, talk exchanges conducted in general accordance with the CP and the conversational maxims are reasonable.

We are not going to defend this argument, however, for even if it is sound, it does not reveal a distinctive feature of conversational maxims - since it is also profitable and therefore reasonable to abide by other maxims such as "Be polite," at least occasionally. The argument can be modified, though, in order to show that it is not only profitable and reasonable to occasionally abide by all conversational maxims, but also necessary. That is, their occasional application is a necessary condition of conversation. In this respect, the conversational maxims are peculiar as they cannot be abandoned unless conversation itself is abandoned.

Grice might have approved of the claim that the occasional application of all conversational maxims is a necessary condition of conversation. In fact, this claim is obtained if we replace the word "profitable" by "possible" in the last sentence of the quotation above. Moreover, in the phrase "general accordance with the Cooperative Principle and the maxims," we read "general" as "occasional." This interpretation is suggested by the preceding clause "given suitable circumstances." By contrast, we do not read "general" as "unlimited," "normal," or "usual." These interpretations would lead to highly disputable assumptions, as empirical research may demonstrate that the $\mathrm{CP}$ and the maxims are not fulfilled 
unlimitedly, or normally, or usually. It is even more doubtful whether an unlimited, normal, or usual application of the conversational maxims is a necessary condition of conversation.

Now, the claim that the occasional application of all conversational maxims is a necessary condition of conversation can be justified by a transcendental argument in the spirit of Kant's transcendental deduction of the categories (B 116-169). A deduction is a proof that establishes some entitlement (B 116), such as the entitlement to use a concept. In his deduction of the categories, Kant attempts to demonstrate the objective validity of the categories by proving that they must be applied to all objects of experience in order to make experience possible. Although Grice does not use the labels "transcendental argument" or "transcendental deduction" in his seminal paper "Logic and Conversation," he explicitly approves of the respective proofs elsewhere:

I have instinctive sympathy toward the idea that so-called transcendental proofs should be thought of as really consisting in reasoned presentation of the necessity, in inquiries about knowledge and the world, of thinking about the world in certain very general ways. (Grice, 1989c, p. 329) ${ }^{3}$

In the following argument we will deduce the maxims collectively, just as Kant does in his transcendental deduction of the categories. Subsequently, we will address each maxim in turn.

A maximally effective exchange of information, as defined in the previous section, is a talk exchange whose participants fulfill all maxims. Conversation ${ }^{4}$ certainly does not collapse if participants in a talk exchange sometimes do not exchange information in a maximally effective way and instead break one or another of the maxims. Grice (1989a, p. 30) distinguishes four ways in which they may fail to fulfill a maxim and thus break it: 1 . They may violate a maxim quietly and unostentatiously, as is the case with lying and deceiving. 2. They may opt out by making plain that they are unwilling to cooperate and observe the maxims, as is the case, for example, with the refusal to testify. 3. They may be faced with a clash of maxims, as in cases where they cannot fulfill all maxims at the same time. 4. They may flout a maxim blatantly, as is the case with the use of irony and metaphors. Only the latter way of breaking a maxim is accommodated and explained in Grice's theory of conversational implicatures. However, all four

\footnotetext{
${ }^{3}$ Here Grice seems to be influenced by the cognitive-mentalistic turn in linguistics and psychology (Chapman, 2005, pp. 85 and 115). In particular, Noam Chomsky's criticism of behaviorism (Chomsky, 1959 ) is highly compatible with Grice's philosophy of language. Chomsky (1966) argues that the language acquisition of children cannot simply be explained by the linguistic input of their social environment, since this input is frequently inadequate, flawed, and insufficient (the "poverty of stimulus" argument). Chomsky infers that every human being must already be equipped at birth with faculties that make acquiring linguistic competence possible, and he proposes both a Language Acquisition Device and a Universal Grammar.

${ }^{4}$ Some philosophers and biologists label any exchange of information as conversation or communication. In this broad sense of the term, some non-human animal species are also capable of conversation even though they do not fulfill (all) conversational maxims. By contrast, we understand conversation in the usual sense as a linguistic exchange between two or more human speakers.
} 
cases have a similar effect on children who are still in the process of acquiring a first language: They impede their learning of form-meaning relations such as lexical meanings.

Children learn their first language mainly through interactions with parents and other adults. These interactions involve, among other mechanisms, listening to conversations, feedback (e.g., repairs), joint attention, and conversational co-presence. Now, suppose speakers never did exchange information maximally effectively, since they constantly broke one or another of the maxims, say, by using irony, speaking metaphorically, lying, deceiving, making statements despite lacking adequate evidence, giving more or less information than required by the audience, making irrelevant remarks, or not expressing themselves perspicuously. Such a linguistic input would be so confusing for children that it would seem a hopeless task for them to recognize a significant number of lexical meanings. But learning and mastering lexical meanings is essential for learning a language. Hence, in the long term, language and conversation are only possible within a community with some maximally effective exchanges of information. As a consequence, the occasional application of all conversational maxims is a necessary condition of language and conversation.

This conclusion is consistent with empirical evidence about first language acquisition. The whole process is largely based on mechanisms to make conversation - and particularly mutual understanding - possible. In this way, children not only learn the conventional character of language but also learn to communicate (maximally) effective and "to observe Grice's cooperative principle in conversation" (Clark, 2014, p. 105). It takes children a long way and much effort to learn how to communicate maximally effective, while they learn to flout the maxims only in a later stage of the acquisition process. For example, they cannot determine the nonliteral meanings of irony before the age of six, and they distinguish the pragmatic purposes of this speech act not until they are nine or ten (Glenwright \& Pexman, 2010). These findings show that in natural settings children learn to observe the maxims before they learn how to break them. Note, however, that empirical research leaves open the question whether languages can be learned under alternative conditions; in particular, it leaves open the question of whether some of Grice's maxims could be abandoned completely. So, empirical findings do not allow inferences to be drawn about what would happen if speakers broke some of the maxims all the time. In particular, we cannot infer that it is impossible for children to learn a language if their fellows never did exchange information maximally effectively. So, the conclusion of our transcendental argument cannot be derived from empirical evidence.

Kant deduces his twelve categories not only collectively, but he addresses each of them in turn in the section "Systematic representation of all synthetic principles of pure understanding" (B 197-274). Accordingly, we now try to demonstrate for each maxim in turn that its occasional application is a necessary condition of language and conversation. We think this can be achieved at least for the particular supermaxim of each category. In all cases, we will apply a simple test: We will ask whether language and conversation can survive if a particular maxim is always broken by all speakers, while the other maxims are, at least sometimes, observed. In particular, we will ask in each case whether adult speakers have to observe the maxim occasionally in order to pass their language to children. 
We start with the maxims of Quality. Why is it indispensable that speakers sometimes observe the supermaxim "Try to make your contribution one that is true"? The answer is that children could not learn lexical meanings if speakers broke it constantly. (We think our arguments can be extended to other kinds of linguistic meaning, but we will limit ourselves to lexical meaning.) Although the lexical meaning of some words can be conveyed by an ostensive definition, in many other cases understanding of lexical meanings requires having some non-trivial true beliefs about the world. This is not to say that speakers first acquire true beliefs and then comprehend lexical meanings on the basis of their beliefs. The point is that the lexical meaning of many words cannot be grasped without having some true beliefs about the objects, properties, or processes to which the word refers. For instance, a person who does not have some true beliefs about grandmothers does not understand the word "grandmother." Admittedly, it is quite difficult to constantly break the submaxim "Do not say what you believe to be false," because it is much easier to tell the truth than to invent lies (Grice, 1989a, p. 29). But if we succeeded, we would prevent children from forming true beliefs and thus prevent them from acquiring knowledge of lexical meanings. It is also difficult to constantly break the other submaxim "Do not say that for which you lack adequate evidence." In exchanges with young children, the standards regarding the adequacy of evidence are quite low. We break the maxim only if we utter statements for which we lack any evidence, as it happens, for example, when we invent a story. Since such utterances usually refer to objects that are not present in the vicinity of the conversation or do not exist at all, they do not contribute to the formation of true beliefs and the acquisition of lexical knowledge. In sum, speakers have to care about the truth of their statements in order to pass language to children; that is, they sometimes have to make true statements backed up by evidence.

However, that is not enough. The maxims of Quality would be perfectly fulfilled if speakers limited themselves to trivial or unfalsifiable utterances such as "A grandmother is a grandmother" or "I do exist." But such utterances will hardly contribute to the acquisition of language skills. To facilitate the acquisition of true beliefs and lexical meanings, some utterances have to be related to the context of conversation in which they are made. That is, they have to be relevant and thus fulfill the only maxim of Relation, viz. "Be relevant." A similar case can be made for the maxims of Quantity, because the maxim "Be relevant" covers many aspects of them. ${ }^{5}$ Children can form true beliefs about the objects of discourse only if some utterances provide new information that fits to the children's (scarce) background assumptions and fulfills their informational needs. This requirement to align utterances to the informational needs of the audience is expressed by the first maxim of Quantity: "Make your contribution as informative as is required (for the current purpose of the exchange)." One may argue that the second maxim "Do not make your contribution more informative than is required" is regularly flouted by parents and other

\footnotetext{
5 One could even argue that the maxims of Relation and Quantity may be merged. However, as this is not the objective of this article, we continue to ask whether adult speakers have to follow the maxims of Quantity occasionally in order to enable children to acquire lexical meanings.
} 
adults when they speak to young children, as they frequently talk to them without regard to the children's informational needs, and reasonably so. However, in some rare moments children have to be provided with exactly the information required for learning lexical meanings. For example, to grasp the lexical meaning of the predicate "grandmother," all they need is to get a simple definition, such as "a grandmother is the mother of one's mother or father," possibly connected with pointing to specific examples. Any more information about grandmothers potentially obscures the reference of the predicate. So, also the second maxim of Quantity has to be observed occasionally.

Finally, in situations where children are to be provided with information required for learning lexical meanings, the information has to be conveyed clearly. Obscure and ambiguous utterances impede the acquisition of lexical competence, because they make it impossible to grasp the connection between words and the objects, properties and processes to which they refer. So, the supermaxim of Manner, viz. "Be perspicuous," and its submaxims "Avoid obscurity of expression" and "Avoid ambiguity" can be defended on the grounds that their occasional observance is necessary for teaching language. The submaxim "Be brief (avoid unnecessary prolixity)" differs from the second maxim of Quantity mainly in the wording, but not with respect to the effects of breaking the maxim. So, the above argument for the indispensability of the second maxim of Quantity applies also to this submaxim of Manner. On the other hand, it may be questioned whether contributions have to be orderly in order to be perspicuous and allow for the transmission of language. As it stands, the submaxim "Be orderly" is too vaguely formulated to allow for a definite judgment, so we are not even going to try to defend it.

One could indeed extend the above arguments on behalf of each maxim and consider possible objections against them. The reason why we have tried to keep them short is that they go far beyond Grice. His own writings suggest that he entertains a collective deduction of the maxims that reveals the cumulative effect of the maxims, but we have tried to demonstrate that at least the supermaxims of each category can be established separately, on the grounds that their observance is a necessary condition for the transmission of language.

In principle, our transcendental reasoning allows also for an extension of the list of conversational maxims. If one suspects Grice's list to be incomplete, any further maxim can be tested for in the same way, by considering whether conversation would collapse in case the maxim was abandoned completely. We expect there to be an essential difference between conversational and non-conversational maxims: We doubt that conversation would collapse if speakers abandoned any non-conversational maxims, such as "Be polite."6

\footnotetext{
${ }^{6}$ Geoffrey Leech distinguishes several maxims of politeness, such as the maxims of generosity, tact, approbation, modesty, agreement, and sympathy. It is disputed whether any of them holds universally, since there is evidence that human cultures vary significantly in the manifestation of politeness (Leech, 2014 , Ch. 4.). We can leave this question open, but we take the immense cross-cultural variation as evidence that the application of these maxims is not a necessary condition of conversation.
} 


\section{Remarks on Transcendental Arguments}

In this final section, we take a closer look at our main transcendental argument given above and compare it to other transcendental arguments. Let us begin with a remark on the concept of a transcendental argument itself. Transcendental arguments are sometimes defined as arguments with a premise of the form " $X$ is a necessary condition of $Y$ " or " $X$ is a necessary condition of the possibility of $Y$," which is sometimes called a transcendental claim, where from the assumption that $Y$ is the case it logically follows that $X$ is the case too (Stern, 2020). ${ }^{7}$ By contrast, our argument aims to establish a transcendental claim as its conclusion. This is in line with most traditional transcendental arguments (cf. Franks, 2005, p. 204), in particular with those of Kant (cf. Pereboom, 2019). Indeed, from the transcendental claim that the occasional application of all maxims is a necessary condition of conversation, and from the trivial assumption that there is conversation, we can conclude that the maxims are applied occasionally. But this result is also trivial and of no interest.

Our second remark concerns the necessity involved in transcendental claims. If it were logical or conceptual necessity, then transcendental claims, if true, would be true (or could be known to be true) solely in virtue of the meaning of their component expressions. In this case, they would be analytical judgments, which "through the predicate ... do not add anything to the concept of the subject, but only break it up by means of analysis into its component concepts, which were already thought in it (though confusedly)“ (B 11). But this does not apply to Kant's transcendental claims, in particular to those defended in his transcendental deduction of the categories. Nor does it apply to the conclusion of our argument, as it is logically possible that there is conversation even if one or another conversational maxim is never applied. Accordingly, the assumptions "there is conversation" and "it is not the case that all conversational maxims are applied occasionally" do not logically entail a contradiction, not even if one adds all conceptual truths. Maxims are broken in many conversations, and we can conceive without contradiction that a particular maxim is broken in every conversation. It is, for example, conceivable that speakers utter irrelevant sentences all the time. Hence, our conclusion falls under the category of synthetic judgments, which, according to Kant, "add to the concept of the subject a predicate that was not thought in it at all, and could not have been extracted from it through any analysis" (ibid.).

At the same time, transcendental claims cannot be established through empirical research. Most transcendental arguments, in particular those in the tradition of Kant, purport to determine the necessary conditions of our mental life (Bardon, 2020; Stern, 2020). But scientific methods are sometimes unsuitable for ascertaining these conditions. In such cases, we have to rely on transcendental arguments.

\footnotetext{
7 We should not ignore the modal difference between the two claims " $X$ is a necessary condition of $Y$ " and " $X$ is a necessary condition of the possibility of $Y$." Boris Rähme (2017, pp. 27-35) suggests that whereas the former is a substitution of the schema "if $Y$, then $X$," the latter has the logical form "necessarily, if $Y$, then $X$." However, from both claims it logically follows that, given that $Y$ is the case, $X$ is the case too.
} 
Transcendental claims do not express empirical cognitions, which "have their sources a posteriori, namely in experience" (B 2); rather, they convey cognitions a priori, which are "independent of all experience and even of all impressions of the senses" (ibid.). So, transcendental claims are synthetic a priori. The same holds for our thesis that the occasional application of all maxims is a necessary condition of language and conversation. Although it is consistent with empirical evidence, it cannot be inferred from the data.

The usual way to test the claim that $X$ is a necessary condition of $Y$ is to seek cases where $Y$ is present, but $X$ is not; alternatively, one could try to bring about $Y$ without $X$. But such a test is not available for transcendental claims since both $X$ and $Y$ obtain anyway. Whereas $Y$ is "some obvious fact about our mental lifesuch as some aspect of our knowledge, our experience, our beliefs, or our cognitive abilities-" (Bardon, 2020), $X$ is questioned only by skeptics, if at all. To test our thesis empirically, one at most could try to build up a community in which one particular conversational maxim is not applied at all and then check to see whether conversation still persisted in the long term.

We are not arguing that it is unfeasible to conduct a long-term experiment in which a bunch of people is told to avoid applying a particular maxim consequently. But any attempt to realize such an experiment would probably face severe practical and ethical obstacles. Instead, we have pursued a thought experiment in the previous section in order to investigate what would happen if speakers never did exchange information maximally effectively since they constantly broke one or another of the maxims. As it seems impossible for children to recognize a significant number of lexical meanings within such an environment, we have concluded that the occasional realization of a maximally effective exchange of information, in which all maxims are fulfilled, is a necessary condition of language and conversation.

One could object that technical progress might make possible a completely different way of learning a language; scientists might invent a device, say, a pill, that makes traditional language acquisition redundant. As a consequence, the application of the maxims might no longer be a necessary condition of conversation. This scenario is, of course, logically possible. But logical possibility and logical necessity are not at issue when it comes to transcendental arguments. The latter do not purport to establish claims about every possible world, but only claims about what is necessary for humans as they actually are by their nature. So, the question is whether the occasional application of all conversational maxims is a necessary condition of conversation for humans as they are. As long as one cannot explain how humans might learn a language without listening to conversations, we need not take the objection too seriously. Admittedly, insofar as technical progress is largely unpredictable, many transcendental claims to the effect that some fact is a necessary condition of another fact are fallible, and they do not provide reasons more compelling than other philosophical arguments. However, it has not been our primary aim to gain certain knowledge here.

The aim of this article was to explain how conversational maxims can be identified. We tried to show that language and conversation are only possible within a community of speakers who occasionally abide by all maxims. If we are right, 
conversational maxims are rules whose occasional application is a necessary condition of language and conversation.

Acknowledgements We would like to thank Rüdiger Harnisch, Geert Keil, Olaf Müller, Nora Olbrisch, Boris Rähme, and the anonymous reviewers for helpful discussions and critical comments on earlier versions of this paper.

Funding Open Access funding enabled and organized by Projekt DEAL.

Open Access This article is licensed under a Creative Commons Attribution 4.0 International License, which permits use, sharing, adaptation, distribution and reproduction in any medium or format, as long as you give appropriate credit to the original author(s) and the source, provide a link to the Creative Commons licence, and indicate if changes were made. The images or other third party material in this article are included in the article's Creative Commons licence, unless indicated otherwise in a credit line to the material. If material is not included in the article's Creative Commons licence and your intended use is not permitted by statutory regulation or exceeds the permitted use, you will need to obtain permission directly from the copyright holder. To view a copy of this licence, visit http://creativecommons.org/licen ses/by/4.0/.

\section{References}

Bach, K. (2012). Saying, Meaning, and Implicating. In K. Allan \& K. M. Jaszczolt (Eds.), The Cambridge Handbook of Pragmatics (pp. 47-67). Cambridge University Press.

Bardon, A. (2020) Transcendental Arguments. In: Internet Encyclopedia of Philosophy. Retrieved from http://www.iep.utm.edu/trans-ar/. Accessed 19 Mar 2020.

Carston, R. (2002): Thoughts and Utterances. The Pragmatics of Explicit Communication. Blackwell.

Carston, R. (2005). Relevance theory, Grice, and the Neo-Griceans. A response to Laurence Horn's 'Current issues in neo-Gricean pragmatics.' Intercultural Pragmatics, 2, 303-320.

Chapman, S. (2005). Grice. Philosopher and Linguist. Palgrave.

Chomsky, N. (1959). A Review of B. F. Skinner's 'Verbal Behavior.' Language, 3, 26-58.

Chomsky, N. (1966). Cartesian Linguistics. A Chapter in the History of Rationalist Thought. Harper \& Row.

Clark, E. V. (2014). Pragmatics in acquisition. Journal of Child Language, 41, 105-116.

Davis, W. (2019). Implicature. The Stanford Encyclopedia of Philosophy (Fall 2019 Edition).

Franks, P. W. (2005). All or Nothing. Systematicity, Transcendental Arguments, and Skepticism in German Idealism. Harvard University Press.

Glenwright, M., \& Pexman, P. M. (2010). Development of children's ability to distinguish sarcasm and verbal irony. Journal of Child Language, 37, 429-451.

Grice, P. (1989a). Logic and Conversation. In P. Grice, Studies in the Way of Words (pp. 22-40). Harvard University Press.

Grice, P. (1989b). Presupposition and Conversational Implicature. In: P. Grice, Studies in the Way of Words (pp. 269-282). Harvard University Press.

Grice, P. (1989c). Metaphysics, Philosophical Eschatology, and Plato's Republic. In: P. Grice, Studies in the Way of Words (pp. 304-338). Harvard University Press.

Grice, P. (1989d). Retrospective Epilogue. In P. Grice, Studies in the Way of Words (pp. 339-385). Harvard University Press.

Habermas, J. (1990). Moral Consciousness and Communicative Action. MIT Press.

Hall, A. (2018). Relevance Theory. In F. Liedtke \& A. Tuchen (Eds.), Handbuch Pragmatik (pp. 87-95). Metzler.

Horn, L. R. (1984). Toward a new taxonomy for pragmatic inference: Q-based and R-based implicature. In D. Schiffrin (Ed.), Meaning, Form, and Use in Context (pp. 11-42). Georgetown Univ. Press.

Horn, L. R. (2005). Current issues in neo-Gricean Pragmatics. Intercultural Pragmatics, 2, 191-204.

Horn, L. R. (2006). More issues in neo- and post-Gricean pragmatics. A response to Carston's response. Intercultural Pragmatics, 3, 81-93. 
Horn, L. R. (2007). Neo-Gricean pragmatics. A manichean manifesto. In N. Burton-Roberts (Ed.), Pragmatics (pp. 158-183). Palgrave Macmillan.

Horn, L. R. (2012). Implying and Inferring. In K. Allan \& K. M. Jaszczolt (Eds.), The Cambridge Handbook of Pragmatics (pp. 69-86). Cambridge University Press.

Kant, I. (1998). Critique of Pure Reason. Cambridge University Press.

Kasher, A. (1976). Conversational Maxims and Rationality. In A. Kasher (Ed.), Language in Focus (pp. 197-216). Reidel.

Kasher, A. (1982). Gricean Inference Revisited. Philosophica, 29, 25-44.

Kasher, A. (1991a). Pragmatics and the Modularity of Mind. In S. Davis (Ed.), Pragmatics (pp. 567582). Oxford University Press.

Kasher, A. (1991b). Pragmatics and Chomsky's Research Program. In A. Kasher (Ed.), The Chomskyan Turn (pp. 122-149). Blackwell.

Keller, R. (1995). Rationalität, Relevanz und Kooperation. In F. Liedtke (Ed.), Implikaturen. Grammatische und pragmatische Analysen (pp. 5-18). Niemeyer.

Leech, G. (2014). The Pragmatics of Politeness. Oxford University Press.

Levinson, S. C. (1983). Pragmatics. Cambridge University Press.

Levinson, S. C. (2000). Presumptive Meanings. MIT Press.

Pereboom, D. (2019). Kant's Transcendental Arguments. The Stanford Encyclopedia of Philosophy (Spring 2019 Edition).

Rähme, B. (2017). Ambition, Modesty, and Performative Inconsistency. In J. P. Brune, R. Stern, \& M. Werner (Eds.), Transcendental Arguments in Moral Theory (pp. 25-45). De Gruyter.

Rolf, E. (1994). Sagen und Meinen. Westdeutscher Verlag.

Rolf, E. (2013). Inferentielle Pragmatik. Zur Theorie der Sprecher-Bedeutung. Erich Schmidt.

Sperber, D., \& Wilson, D. (1995). Relevance. Blackwell.

Stern, R. (2020). Transcendental Arguments. The Stanford Encyclopedia of Philosophy (Fall 2020 Edition).

Traugott, E. C. (2012). Pragmatics and Language Change. In K. Allan \& K. M. Jaszczolt (Eds.), The Cambridge Handbook of Pragmatics (pp. 549-565). Cambridge University Press.

Publisher's Note Springer Nature remains neutral with regard to jurisdictional claims in published maps and institutional affiliations. 